CLINICAL IMAGES

\title{
Nonsurgical Treatment of Two Cases of Infantile Facial Growths in a Resource-Poor Setting
}

\section{Case Presentations}

Two female infants, aged 11 months and 2 months, presented to our rural clinic in Indonesia within an 8 -month period. The 11-month-old girl had multiple facial growths that developed from 2 months of age and, per her mother's account, caused increasing difficulty with feeding and snoring. The child had been treated with oral steroids, antibiotics, and inhaled beta-agonists with no improvement. She was referred to Jakarta for surgery, but the family had no resources to travel. They came to our clinic as a last resort (Figure 1A). After treatment for just 1 month, the stridor and poor feeding resolved and the child gained $1.4 \mathrm{~kg}$. After treatment for 10 months, the lesions had shrunk substantially and became duller in color (Figure 1B), and treatment was tapered off.

The 2-month-old girl presented with a facial growth, which was noted at approximately 1 week of age as a small bump and had subsequently enlarged to $2 \mathrm{~cm}$ (Figure 2A). This child had no other symptoms. After treatment at our clinic for 9 weeks, the lesion shrank and the color faded (Figure 2B).

\section{Questions}

What is the diagnosis for both of these children? What treatment was used to obtain this result?
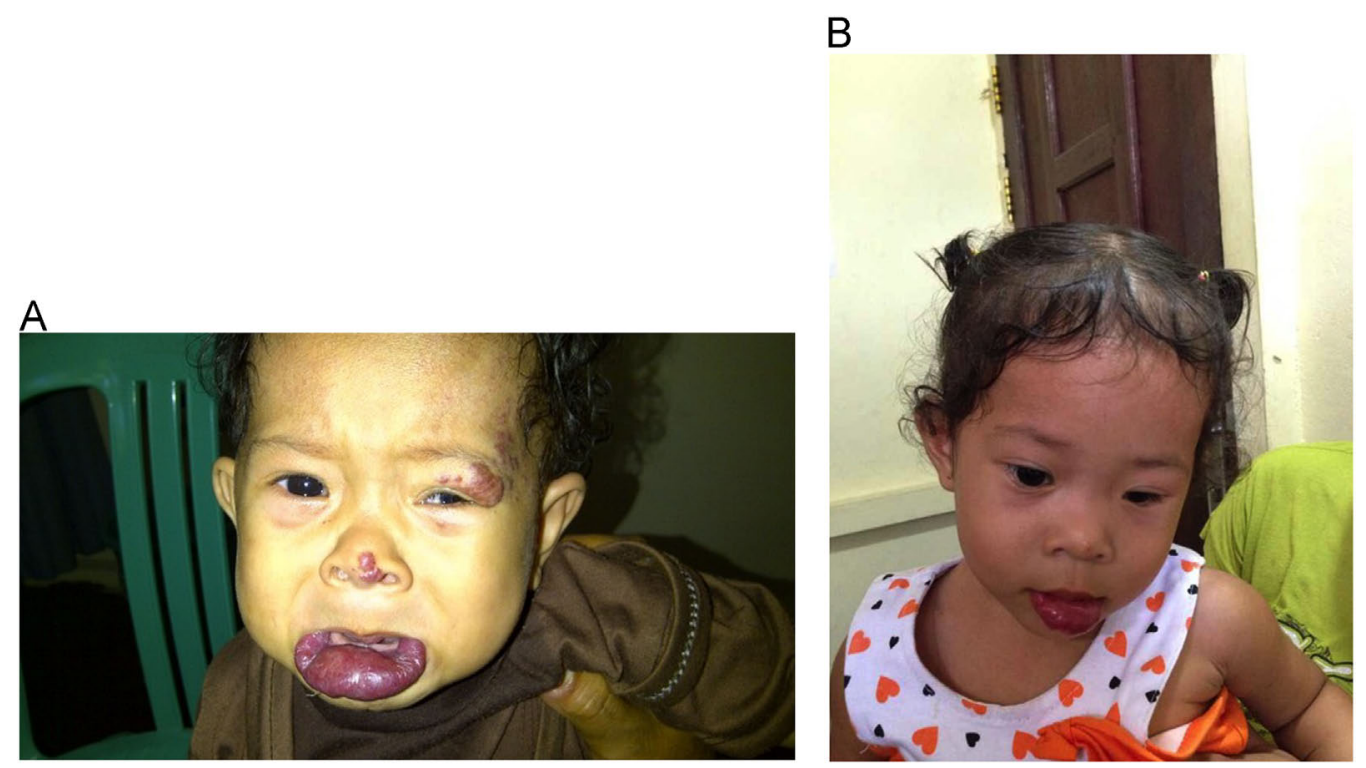

Figure 1. (A) An 11-month-old girl (weight $5.6 \mathrm{~kg}$; stridor at rest) with multiple bright red, disfiguring facial lesions at the beginning of treatment. (B) The 22-month-old girl after 8 months of treatment (treatment had been stopped for 2 months at the taking of this photo). She has no stridor, and lesions have decreased in size, flattened, and become duller in color. 


\section{Answer: Complex Infantile Hemangiomas}

These children had complex infantile hemangiomas, which were treated with oral propranolol (oral propranolol 3 times daily, with a total daily dose of 1 to $2 \mathrm{mg} / \mathrm{kg}$ ).

Infantile hemangiomas affect approximately 5\% of infants. ${ }^{1}$ They are not present at birth, but usually manifest at 2 to 4 months of age. They proliferate for a few months and then involute over a period of years. Usually, they are benign and single and do not require treatment. However, complex cutaneous hemangiomas, defined as having large or multiple lesions, or large size, often on the face, can cause disfigurement and functional impairment. Even when the lesions involute, the resulting skin is a discolored, fibrous tissue. Large hemangiomas can also ulcerate. Infantile hemangiomas in the brain, liver, gastrointestinal tract, and airway can cause life-threatening complications, including stroke, hemorrhage, and respiratory distress and failure.
Medical providers are not taught how to treat these lesions, and patients with complex infantile hemangiomas are referred to specialists instead. Treatment has historically been complex. Surgical treatment can be associated with significant morbidity and scarring. Treatment with corticosteroids and vincristine also can have complications and mixed results. ${ }^{2}$ However, in 2008, the serendipitous observation of the involution of a cutaneous hemangioma in a child treated with propranolol for cardiomyopathy ${ }^{3}$ led to a change in the treatment paradigm for infantile hemangiomas. Case series have demonstrated remarkable effectiveness with the use of propranolol as a first-line agent in the treatment of complex infantile hemangiomas, even in areas without resource contraints. ${ }^{4,5}$

Propranolol is generally started at $1 \mathrm{mg} / \mathrm{kg}$ divided 3 times daily and increased to $2 \mathrm{mg} / \mathrm{kg}$ divided 3 times daily. It is essential to check vital signs, with special attention to the heart rate, and to perform a careful physical

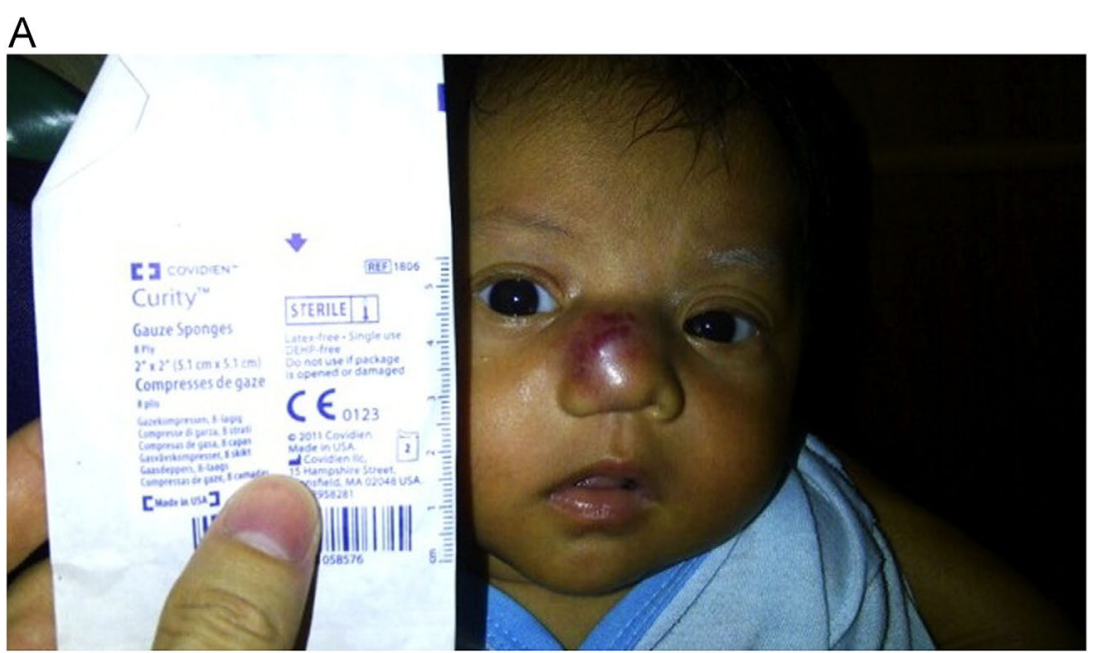

B

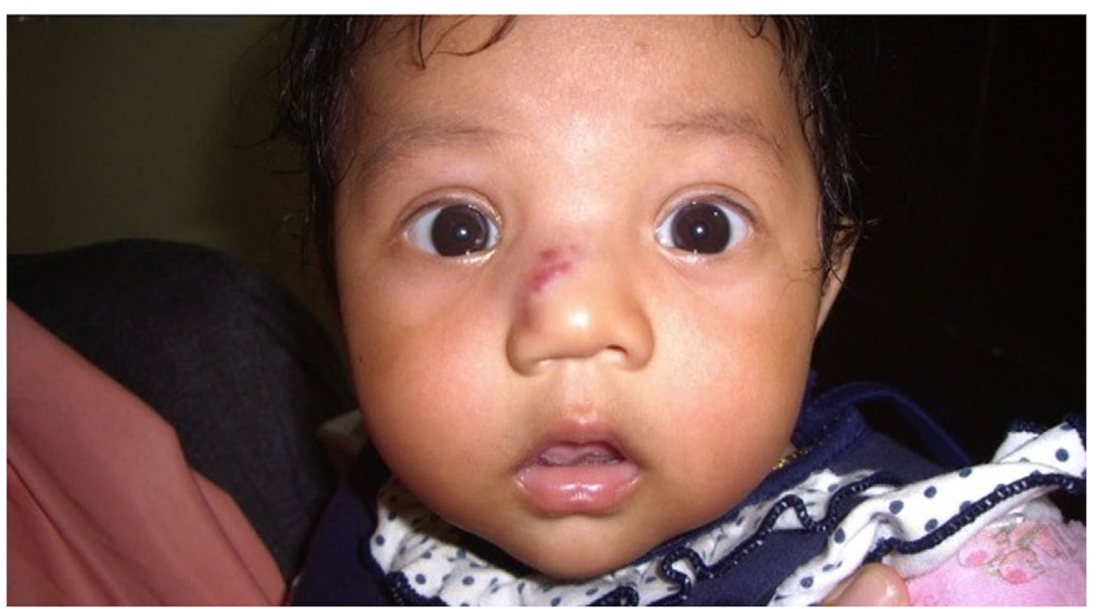

Figure 2. (A) A 2-month-old girl with a single facial lesion $2 \mathrm{~cm}$ in size. (B) The same child at 4 months of age, after 8 weeks of treatment. 
examination to check for associated neurocutaneous syndromes. The child should be monitored for 3 to 4 hours after the first dose or any increase in dose for complications, namely, hypoglycemia, bradycardia, and bronchospasm. Parents must be educated regarding signs and symptoms of side effects of propranolol and instructed to withhold the medication if the child does not feed or vomiting develops. When the child is approximately 1 year of age or has been receiving the medication for 4 to 6 months, the propranolol can be tapered off. If the lesions increase in size, propranolol can be restarted.

In summary, although complex infantile hemangiomas are relatively rare, general medical providers (especially those practicing in resource-poor settings) should be aware of the efficacy of propranolol to treat infants with disfiguring or life-threatening complex infantile hemangiomas.

\section{Acknowledgment}

We would like to acknowledge Anna Messner, MD, of the Department of Otolaryngology/Head \& Neck Surgery at Stanford University.

Ronald Natawidjaja, MD Alam Sehat Lestari Clinic, West Kalimantan Borneo, Indonesia
N. Ewen Wang, MD

Department of Surgery, Division of Emergency Medicine, Stanford University School of Medicine,

Stanford $C A$

\section{References}

1. Schupp CJ, Kleber JB, Gunther P, Holland-Cunz S. Propranolol therapy in 55 infants with infantile hemangioma: dosage, duration, adverse effects, and outcome. Pediatric Dermatol. 2011;28:640-644.

2. Price CJ, Lattouf C, Baum B, et al. Propranolol vs corticosteroids for infantile hemangiomas: a multicenter retrospective analysis. Arch Dermatol. 2011;147: 1371-1376.

3. Léauté-Labrèze C, de la Roque ED, Hubiche T, Boralevi F, Thambo J-B, Taïeb A. Propranolol for severe hemangiomas of infancy. N Engl J Med. 2008;358:2649-2651.

4. Manunza F, Syed S, Laguda B, et al. Propranolol for complicated infantile haemangiomas: a case series of 30 infants. Br J Dermatol. 2010;162:466-468.

5. Theletsane T, Redfern A, Raynham O, Harris T, Prose NS, Khumalo NP. Life-threatening infantile haemangioma: a dramatic response to propranolol. J Eur Acad Dermatol Venereol. 2009;23:1465-1466. 